\title{
Chemical composition, fungal microflora and mycotoxin content in maize silages infected by smut (Ustilago maydis) and the effect of biological and chemical additives on silage aerobic stability
}

\author{
A. Potkański ${ }^{1,4}$, J. Grajewski³ ${ }^{3}$ M. Twarużek ${ }^{3}$, M. Selwet ${ }^{2}$, \\ B. Miklaszewska ${ }^{3}$, A. Błajet-Kosicka ${ }^{3}$, M. Szumacher-Strabel ${ }^{1}$, \\ A. Cieślak ${ }^{1}$ and K. Raczkowska-Werwińska ${ }^{1}$ \\ Poznań University of Life Sciences, \\ ${ }^{1}$ Department of Animal Nutrition and Feed Management, \\ ${ }^{2}$ Department of Agricultural Microbiology \\ Wotyńska 33, 60-637, Poland \\ ${ }^{3}$ Kazimierz Wielki University, Section of Physiology and Toxicology \\ Chodkiewicza 30, 85-064 Bydgoszcz, Poland
}

(Received 30 June 2009; revised version 30 October 2009; accepted 29 January 2009)

\begin{abstract}
Maize attacked by the facultative biotrophic smut pathogen, Ustilago maydis (Basidomycetes) was ensiled in microsilos in two combinations of infected and non-infected plants, with or without biological (Polmasil) or chemical (Kemisile 2000) additives. The silage was subjected to chemical and microbiological analyses. The aerobic stability of the silage was tested. Ustilago maydis constituted up to $6.22 \%$ of the total yeast content $\left(\mathrm{CFU} \mathrm{g}^{-1}\right)$ in the infected and $0.22 \%$ in the noninfected material. Silage made from infected plants had a higher content of fungi (6.45 vs 4.54), moulds (6.20 vs 4.54), and yeast (6.08 vs 3.71) expressed as $\log _{10}$ CFU g ${ }^{-1}$ as compared with noninfected plants. The use of the chemical additive decreased these effects. The contents of ochratoxin, zearalenone, and deoxynivalenol were low and did not change during the ensiling. The cytotoxicity test did reveal toxicity of silage from infected plants, however. It seems that the observed toxicity is the effect of toxins other than those assayed.
\end{abstract}

KEY WORDS: maize silage, mycotoxins, Ustilago maydis, aerobic stability

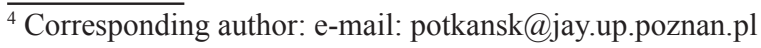




\section{INTRODUCTION}

Maize silage is the basic feed used in dairy and beef production, which is why cattle breeders are interested in the consequences of ensiling plants infected by smut. Maize smut (Ustilago maydis) is a fungal disease that occurs in Poland and other countries at varying intensities depending on the weather and agro-technical conditions, the occurrence of other fungal diseases and pests. Smut can affect the entire above-ground plant parts, leading to development of characteristic galls that cause significant losses in yields and nutritive value of forages intended for silage production (Du Toit and Potaky, 1999). As a rule, the ensiled maize manufactured from infected raw material is attacked by other mould fungi from different genera (Fusarium, Aspergillus, and Penicillium), their metabolites, and by other undesirable microorganisms - bacteria (Coli, Clostridium) and yeast, in particular. All of these can negatively impact the ensiling process, increase nutrient losses, and decrease the nutritive value of the silage. The presence of these microorganisms is particularly critical after opening the silo, when contact with oxygen leads to the deterioration of the ensiled material. There are also a few reports that smut (Ustilago maydis) can produce toxic ergo-alkaloids that reduce the value of the silage and are cytotoxic. The aim of the experiment was to assess the chemical composition, fungal microflora composition, occurrence of some mycotoxins, and aerobic stability of silage manufactured from smut-infected maize.

\section{MATERIAL AND METHODS}

Silage was prepared from the maize (Zea mays L.) hybrid Celux (FAO 220) with a 40 to $44.7 \%$ dry matter content. Maize for the experiments was harvested on September, 2006. The plant material was divided into two parts, where the first batch contained non-infected plants and the second, smut-infected plants. Each of these batches was ensiled in the following three combinations: without silage additives, with the chemical additive KemiSile 2000, or supplemented with the biological additive Polmasil. Each combination was ensiled in three replications. Following chopping, the plants were ensiled in polyethylene micro-silos with a 41 capacity, sealed with a rubber stopper allowing the release of gaseous products.

The biological additive contained the following components: Enterococcus faecium M74, Lactobacillus casei, Lactobacillus plantarum and Pediococcus spp. at a concentration of $10^{9} \mathrm{CFU}$ (colony forming units), while the chemical additive contained, in \%: formic acid 55, propionic acid 9, benzoic acid 5, ammonium formate 24, and benzoic acid ester 7 (Kemira OY, Finland).

The microsilos were opened after 60 days. Half of the silage from each silo 
was used for chemical analysis, the second half was divided into two equal parts, one of which was used for microbiological analysis and the other for tests on aerobic stability followed by chemical and microbiological analyses.

The stability test was conducted by the Honig method (1986), developed by O'Kiely (1998). The silage samples were placed in boxes in which holes were made to allow air circulation. Each box was connected to an electronic temperature meter (Squirrel). The temperature was recorded during the entire period of exposition of the sample to oxygen ( 7 days) and the obtained data were subjected to mathematical and graphic analyses using Squirrelwise and Excel software.

The chemical composition of the fresh material and silage was determined according to AOAC (1996). ADF and NDF were estimated according to Van Soest et al. (1991) and simple sugars according to McDonald and Henderson (1964). The silage $\mathrm{pH}$ was determined using a CP-104 $\mathrm{pH}$-meter equipped with a replaceable electrode. Ammonia was estimated according to the Nessler method (SzumacherStrabel et al., 2002). Lactic, acetic and propionic acids were determined using a Hewlett-Packard HP 1050 chromatograph equipped with a UV detector, a Supelcogel C-610H column (Supelco), and a $2 \mathrm{~m}$ long glass column $0.6 \mathrm{~mm}$ in diameter filled with a Supelco filter type GP $10 \% \mathrm{SP}-1200 / 1 \% \mathrm{H}_{3} \mathrm{PO}_{4}$, on $80 / 100$ Chromosorb WAW.

Microbiological analyses of the experimental fresh material and silage included the determination of: total number of mesophilic bacteria, mould fungi and yeast (oxytetracycline-glucose-yeast extract agar, Oxoid), lactic fermentation bacteria (APT agar, Merck), Clostridium (TSC agar, Merck), and bacteria from the Coli group (Chromocult agar, Merck). The number of Ustilago maydis colonies was assessed in the fresh material and silage. In addition, the total quantity of $\mathrm{B}_{1}$, $B_{2}, G_{1}$ and $G_{2}$ aflatoxins (AFLA), ochratoxin A (OTA) and zearalenone (ZEN) were determined by HPLC (Merck-Hitachi) with fluorescent detection, whereas UV detection was used for deoxynivalenol (DON). Before chromatography, the extracted samples were purified on immunological affinity columns. A derivation system from KobraCell was employed to determine aflatoxins.

Apart from the quantitative determination of individual mycotoxins, a cytotoxicity test (MTT) was carried out using a cell culture of porcine kidneys allowing the limit toxic concentrations of the examined material to be determined (Hanelt et al., 1994). Mould fungi and yeast were taxonomically identified according to Fassatiova (1983), Kwaśna et al. (1991), Pitt and Hocking (1999), Pitt (2000), Samson and Hoekstra (2000) and Samson and Frisvad (2004).

All data were tested for normality by the Shapiro-Wilks W test, $\mathrm{P}<0.05$. The original data of fungal and bacterial counts were log transformed before analysis of variance. Three-way ANOVA (model I) without replication was performed for validation of experimental factors (at $\mathrm{P}=0.05,0.01$, and 0.001 ). Each factor (A - 
stability test, $\mathrm{B}$ - preparation and $\mathrm{C}$ - smut effect) was tested over the mean square of the third order interaction $(\mathrm{A} \times \mathrm{B} \times \mathrm{C})$ which represents error variance.

\section{RESULTS}

Fresh material from the smut-infected maize was found to contain smaller quantities of N-free extractives (NFE) and sugars than smut-free fresh material (Table 1), but similar differences in the chemical composition were not found in the silage manufactured from those materials. Both types of silage had good quality, a favourable $\mathrm{pH}$ and contained significant quantities of lactic acid, trace amounts of butyric acid and minimal quantities of ammonia. The chemical and biological silage additives did not exert a significant influence on their composition. After stability tests, the amount of lactic acid in the silage decreased significantly, the $\mathrm{pH}$ increased and the amount of butyric acid increased considerably. These changes were less conspicuous in silage with the chemical additive (Table 2). Both smut-infected and smut-free fresh maize materials were found to contain very similar quantities of mesophilic and lactic bacteria, mould fungi and yeast. In comparison with the control samples, smut-infected maize was characterized by higher levels of moulds $\left(\log _{10} \mathrm{CFUg}^{-1} ; 7.32\right.$ vs 6.50) with Fusarium proliferatum as the dominant species (67\% of the total) (Table 3). In the case of both green forages, only small quantities of ochratoxin A (OTA) and zearalenone (ZEN) were detected, while the levels of deoxynivalenol (DON) were higher: $366 \mathrm{ppb}$ in smut-free forage and $340 \mathrm{ppb}$ in those infected by smut (Table 1). No aflatoxins (AFLA) were determined in the examined samples. Smut-infested fresh maize was characterized by low toxicity in the MTT test. In addition, no ergoalkaloids were found in examined samples.

In comparison with the initial fresh material, the quantities of mesophilic and lactic bacteria, mould fungi and yeast were found to be lower in silages (Table 3). In silage made from the smut-infected maize without additives, the mould fungi and yeast counts were substantially higher than in silage prepared from the smut-free material, but this difference was not observed when additives were used (Table 3). In fact, when KemiSile was added, the amount of mould fungi was lower in the silage prepared from smut-infected plants than from smut-free plants. Penicillium roqueforti, in a proportion of over $90 \%$, was the dominant mould species in all types of silages. Although $6.22 \%$ of Ustilago maydis in yeast was determined in the smut-infected plants and $0.20 \%$ in healthy plants, the presence of this yeast was not detected in the silage. 


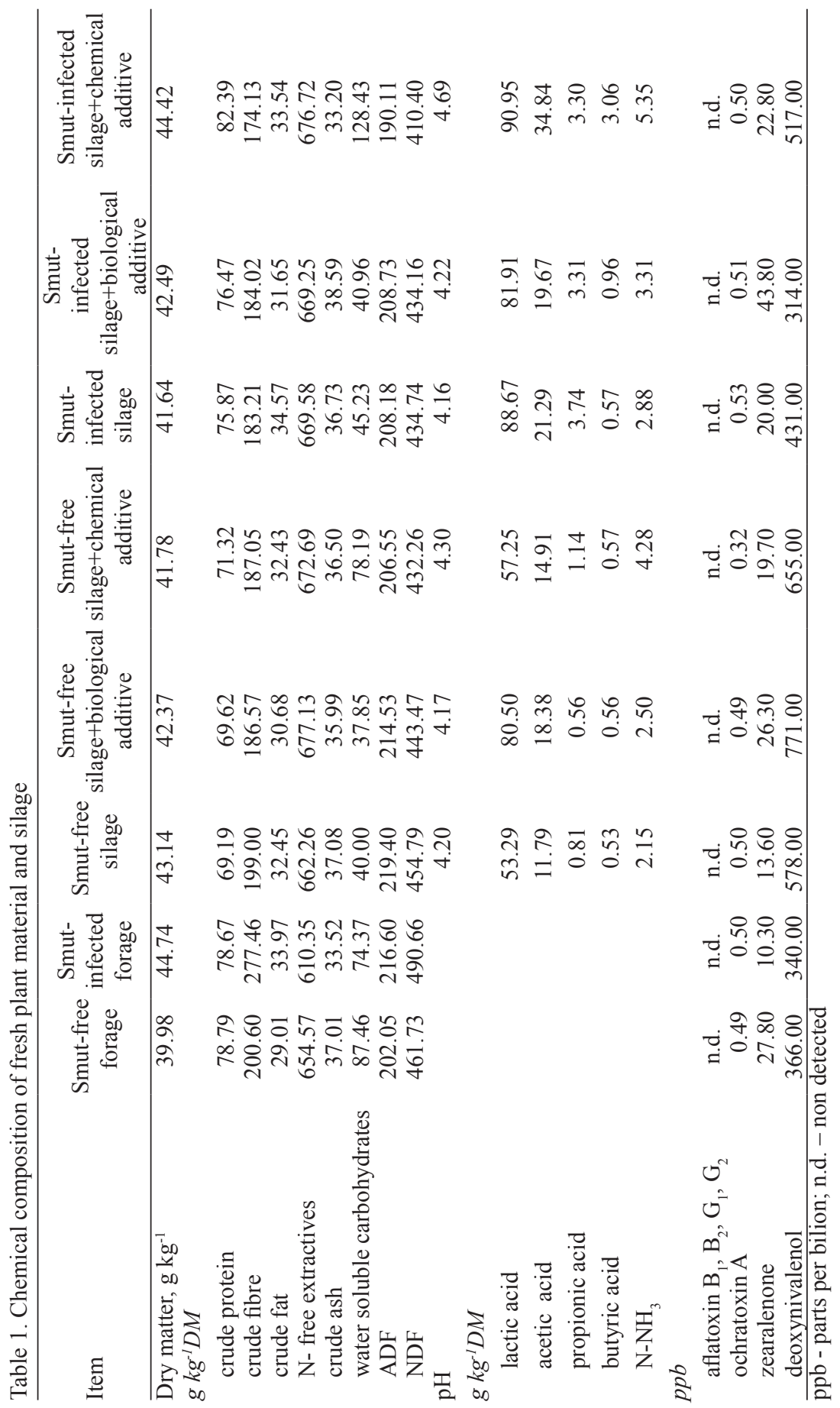




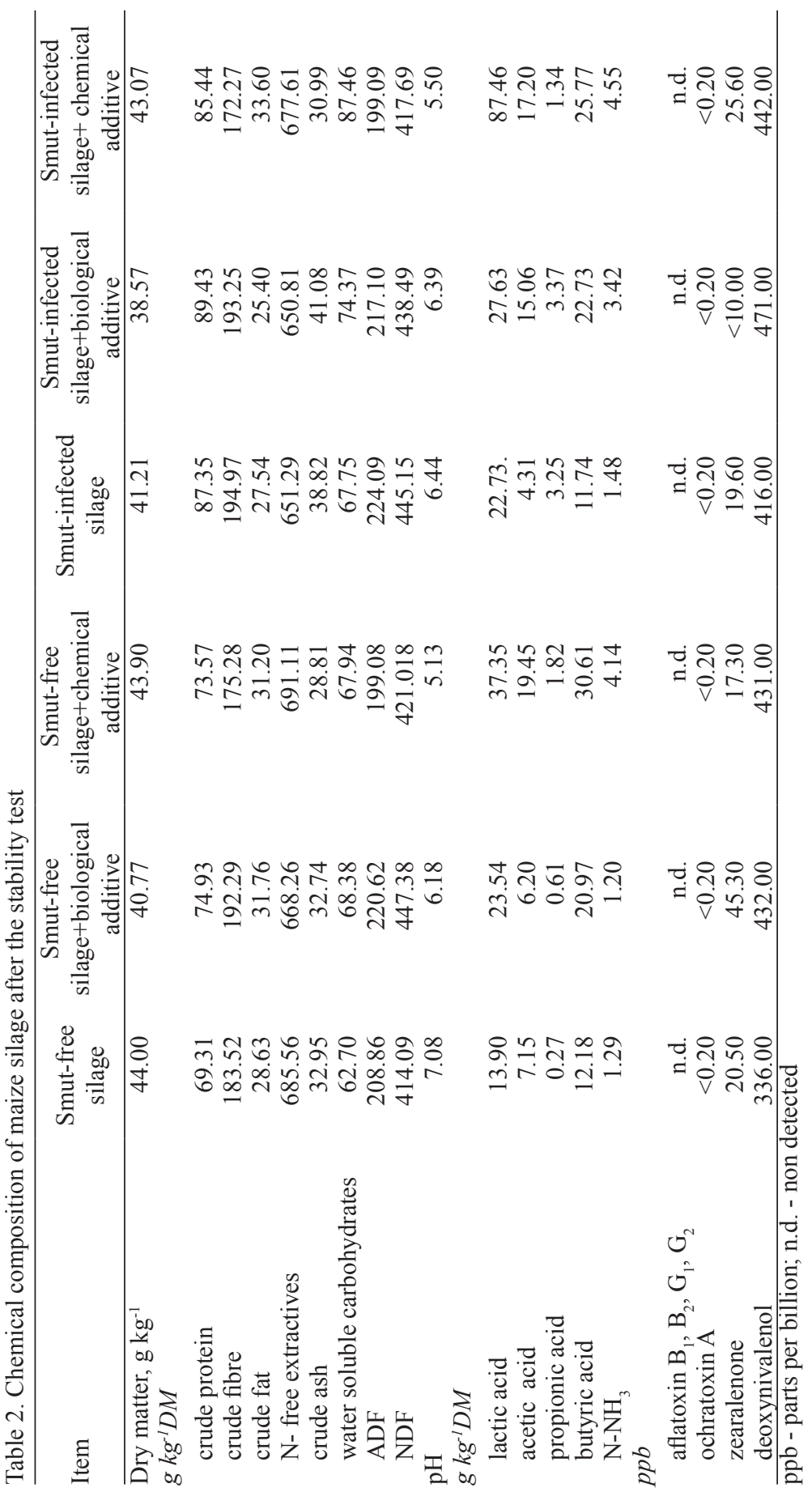




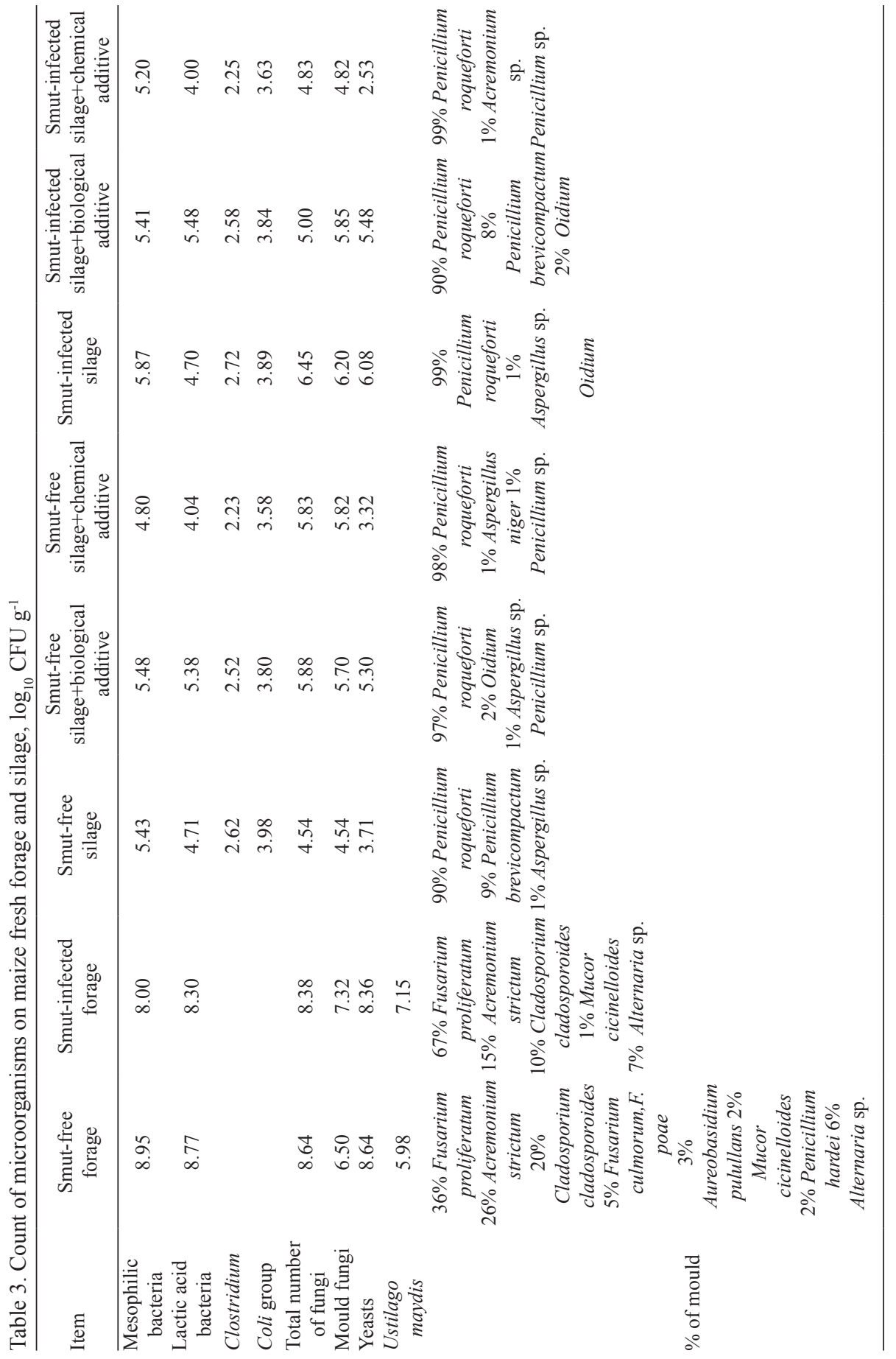


Ochratoxin A (OTA) and zearalenone (ZEN) were determined in all types of silage as well as in the fresh plant materials, both in the control group and in the smut-infected plants. The amounts of deoxynivalenol (DON) increased in the silage but were lower in the silage from the smut-infected plant material.

In the MTT test, the quantities of mesophilic and lactic bacteria, mould fungi and yeast in the silage increased again after the stability test (Table 4) and they were statistically significant (Table 6). No changes in the mycotoxin content in the silage were observed and deoxynivalenol (DON) continued to be dominant. The quantity of mould fungi was found to increase less rapidly in the silage supplemented with the chemical additive. Significant changes in the mould species composition were determined in the silage prepared from the smut-free plant material with silage additives, though Penicillium roqueforti continued to be dominant. In other treatments, Oidium was prevalent, while the percentage of Penicillium roqueforti dropped. Before the aerobic exposure, the majority of the silage failed to exhibit cytotoxicity, except for the low toxicity of silage treated with the biological additive, Polmasil (MTT test). After the aerobic exposure all of the silage produced from the smut-infected plant material was characterised by cytotoxicity as demonstrated in the MTT test. The highest cytotoxicity was found in the silage from the control group (Table 5).

\section{DISCUSSION}

Smut is a fungal disease (caused by Ustilago maydis) which, under unfavourable conditions, may affect considerable numbers of maize plants in the field, especially during periods of drought followed by heat waves. The disease attacks all of the above-ground plant parts and the developing galls produce enormous quantities of spores (teliospores) causing fresh infections. Several generations of these teliospores may develop during the course of the vegetation period, but in Poland usually only one or two generations develop. Smut reduces the yield and quality of maize forage. Methods of controlling it are limited primarily to seed dressing. The cultivar list of maize has lately included some cultivars with a higher resistance to smut.

In the present study an attempt was made to determine to what extent the presence of smut-infected plants influences the nutritional value of maize silage. It is generally accepted that the presence of smut decreases the amount of $\mathrm{N}$-free extractives and simple sugars in green forage and this fact was also confirmed in the present experiments. Similar differences were not found in the silage, however, which could be attributed to the fact that the majority of sugars underwent lactic fermentation and their quantities in the silage depended primarily on the course of 


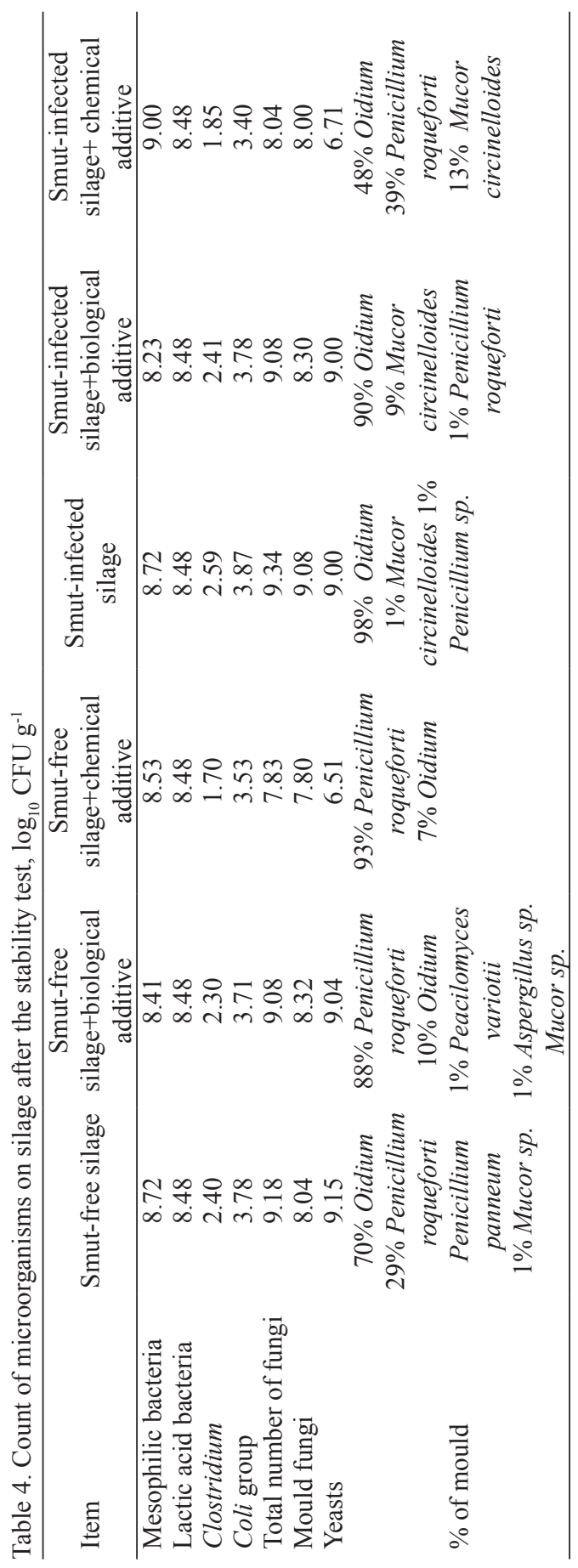




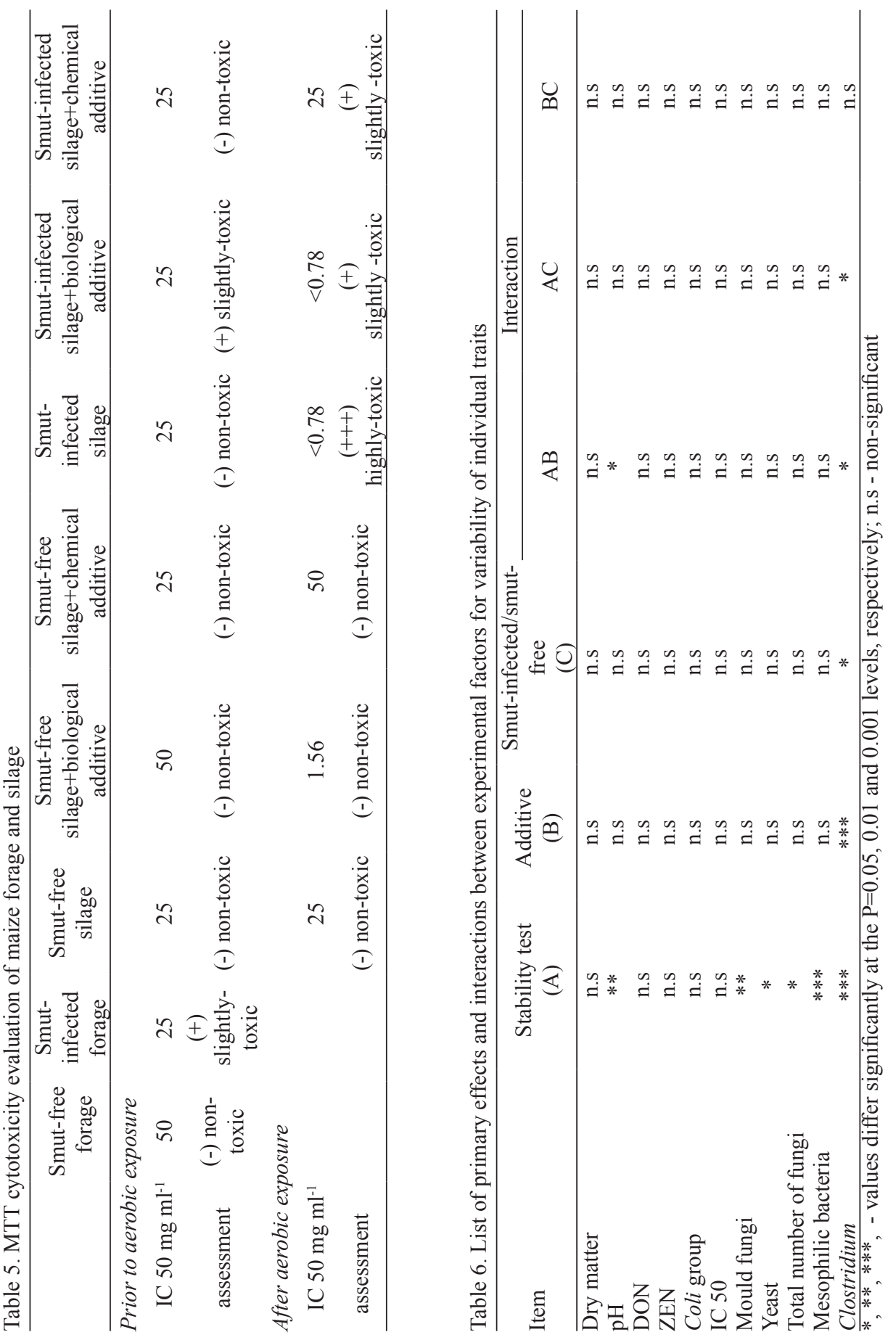


fermentation and the silage additives used.

The raw material for ensiling was rich in epiphytic microflora, including mould fungi. In our earlier studies on the value of maize silages, similar data regarding the content of individual groups of microorganisms were also obtained (Grajewski et al., 2007; Selwet et al., 2008).

Silage raw materials may also contain mycotoxins produced by moulds. In the case of fresh maize forage, these may include zearalenone (ZEN) and deoxynivalenol (DON), the mycotoxins produced by Fusarium spp. In the current experiments, ZEN and DON were found to occur at the same levels as in our earlier studies (Grajewski et al., 2007). In the course of the ensiling process and after opening the silo, conditions may favour the development of mould fungi belonging to the genera Penicillium and Monascus, which also produce other mycotoxins, such as roquefortin, mycophenolic acid, monacolin, and citrinin. These mycotoxins were not determined in the present investigation, however.

As not all mycotoxins or toxins were investigated, the MTT test, which allows the assessment of total cytotoxicity, was extremely valuable.

The contents of individual groups of undesirable microorganisms, after the silos were opened, did not differ significantly for the silage prepared from the smut-infected and smut-free raw materials and were lower than in fresh forage. On the other hand, these quantities increased when the silage was exposed to oxygen during the stability test. Silage prepared from smut-infected maize with or without biological additives exhibited particularly poor stability during this test, whereas silage prepared with the chemical additive was more stable (the level of moulds was lower). Aerobic exposure activated the development of the yeast-derived mould, Oidium, especially in the smut-infected silage. During their development, these organisms deacidify the raw material by using lactic acid as a carbon source, thus deteriorating the material's stability. Yeast-derived moulds become active even at low oxygen concentrations (microaerophiles) and may therefore cause a deterioration in the taste and smell of the silage. Some of these microorganisms are considered to be pathogenic. The MTT test revealed the amount of mycotoxins did not change significantly during the ensiling process, there was a change in the composition of the fungal microflora. It is possible that the observed increase in cytotoxicity could have been caused by metabolites that were not determined in this experiment (masked mycotoxins).

No colonies of actively growing Ustilago maydis were isolated from the silage after the ensiling process and the aerobic stability test. According to Bauer (2004), the majority of mycotoxins occur in silage in small quantities and that do not cause serious harm to the health and productivity of ruminants. Higher quantities were found in earlier investigations on the value of maize silage, especially in the case of deoxynivalenol (DON). According to Richter (2002), however, this mycotoxin 
may undergo reduction in the course of the ensiling process. Until recently, no standard acceptable levels of the most common mycotoxins (ZEN, DON, OTA, AFLA) in silages for ruminants have been published.

It appears on the basis of this study that chemical additives could be useful when ensiling smut-infected maize, as these compounds inhibit the development of some groups of microorganisms, including mould fungi. To prove their significance, however, additional experiments will be required. It would be expedient to investigate greater quantities of trichothecenes of groups A and B in silage infected with smut.

\section{CONCLUSIONS}

In conclusion, silage obtained from maize plants infected with smut (Ustilago maydis) does not necessarily differ significantly from that made from smut-free plant material, but it generally has worse aerobic stability and quality, as confirmed by the positive results of the performed MTT cytotoxicity test. The identification of the toxins responsible will require further investigation. The colonies of Ustilago maydis found in fresh maize forage were absent in the silage. The inclusion of chemical silage additives before ensiling can in part prevent deterioration of silage quality when using smut-infected plants.

\section{REFERENCES}

AOAC, 1996. Association of Official Analytical Chemists, Official Methods of Analysis. $16^{\text {th }}$ Edition. Washington, DC

Bauer J., 2004. Pilzstoffwechsel Produkte in Silage: Einfluss auf die Gesundheit von Wiederkäuern. In: Mycotoxins and Pathogenic Mould in the Environment. VIIth International Conference, Bydgoszcz (Poland), p. 22 (Abstr.)

Du Toit J., Potaky J.K., 1999. Effect of silk maturity and pollination on infection of maize ears by Ustilago maydis. Plant Dis. 83, 621-626

Fassatiova O., 1983. Microscopic Fungi in Technical Microbiology (in Polish). PWN, Warszawa

Grajewski J., Potkański A., Raczkowska-Werwińska K., Twarużek M., Miklaszewska B., Grabowska M., Gubała A., Selwet M., 2007. Hygienic quality of corn silage with a biological and chemical additive. Med. wet. 63, 205-208

Hanelt M., Garies M., Kollarczik B., 1994. Cytotoxicity of mycotoxins evaluated by the MTT cell culture assay. Mycopathologia 128, 167-174

Honig H., 1986. Evaluation of aerobic stability. In: Proceedings of the Eurobac Conference. Uppsala (Sweden). Grass Forage Rep. 3, 76-82

Kwaśna H., Chełkowski J., Zajkowski P., 1991. Fungi, Vol. XXII (in Polish). Warszawa-Kraków

Mc Donald P., Henderson A.R., 1964. Determination of water-soluble carbohydrates in grass. J. Sci. Food Agr. 15, 395-398 
O'Kiely P., 1998. Characteristics of silage making in Ireland. Farm and Food Research, Teagasc. Dublin (Ireland) 8 (2), 6-11

Pitt J.I., Hocking A.D., 1999. Fungi and Food Spoilage. Aspen Publication Aspen Publishers, Inc. Gaithersburg, MA(USA)

Pitt J.I., 2000. A Laboratory Guide to Common Penicillium Species. Food Science. Australia Joint Venture of CSIRO and AFISC. North Ryde, p. 197

Richter W.J.F., 2002. Vorkommen und Abbau von Deoxynivalenol (DON) in Silage. In: VIth International Conference: Mycotoxins in the Environment of People and Animals. Bydgoszcz (Poland), pp. 171-177

Samson R.A., Frisvad J.C., 2004. Penicillium subgenus Penicillium: New Taxonomic Schemes, Mycotoxins and Other Extrolites. Centraalbureau voor Schimmelcultures, Utrecht (The Netherlands)

Samson R.A., Hoekstra E.S., 2000. Introduction to Food and Airborne Fungi. Centraalbureau voor Schimmelcultures, Utrecht (The Netherlands)

Selwet M., Raczkowska-Werwinska K., Potkański A., Grajewski J., Twarużek M., Miklaszewska B., Łukomska W., Gubała A., 2008. Chemical composition and microflora of silage from maize ensilage with bacterial and chemical additives. Med. wet. 64, 477-479

Szumacher-Strabel M., Potkański A., Kowalczyk J., Cieślak A., Czauderna M., Gubała A., Jędroszkowiak P., 2002. The influence of supplemental fat on rumen volatile fatty acid profile, ammonia and $\mathrm{pH}$ levels in sheep fed a standard diet. J. Anim. Feed Sci. 11, 577-587

Van Soest P.J., Robertson J.B., Lewis B.A., 1991. Methods of dietary fiber, neutral detergent fiber and non-starch polysaccharides in relation to animal nutrition. J. Dairy Sci. 74, 3583-3593 